\title{
Pengarahan Pusat Pertumbuhan melalui Analisis Keunggulan Komparatif di Kabupaten Garut
}

\author{
Endah Djuwendah, Hepi Hapsari dan Erna Rachmawati \\ Jurusan Sosial Ekonomi Fakultas Pertanian Universitas Padjadjaran \\ Jl Raya Jatinangor Km 21 Bandung 40600 \\ Korespondensi: endah_djuwendah@yahoo.com
}

\begin{abstract}
The guidance for center of growth and services area through comparative advantage analysis in of Garut District
\end{abstract}

The agricultural sector plays an important role in social economic life of Garut district. Therefore, regional development strategies in accordance with the potential agricultural resources are absolutely necessary in Garut district. The aims of this research were to identify superior agricultural commodities that could become the priority to be developed and to know a hierarchy system between service and growth areas which suppor regional development in Garut. Research design was descriptive survey using 42 district in Garut Regency as analysis unit. Research objects was agricultural sector production and economic and social facilites. The results showed that superior agricultural commodities to be developed were food crops namely rice, peanut, soybean, corn and cassava; and horticultural commodities such as potatoes, chili, carrots tomato, avocado, tangerine, banana and papaya. Superior agricultural commodities were localized in several sub-districts. The 31 sub-districts $(73.81 \%)$ had a tendency of specialization of agricultural activities, while 11 sub-districts (26.19 $\%$ ), did not specialize in some specific commodities. Sub district of Karangpawitan Garut City was point of growth. There were six sub-district as the main service centers, 13 district as a local service center and the 23 district which became the center of the smallest service.

Key words: Comparative advantage, Growth center, Service center.

\begin{abstract}
ABSTRAK
Sektor pertanian berperan penting dalam kehidupan sosial ekonomi masyarakat Kabupaten Garut. Oleh karena itu strategi pengembangan daerah yang sesuai dengan potensi sumberdaya pertanian mutlak diperlukan di Kabupaten Garut. Penelitian ini bertujuan untuk mengetahui komoditas pertanian yang menjadi unggulan untuk dikembangkan dan sistem hierarki pusat-pusat pelayanan dan pertumbuhan yang mendukung pengembangan wilayah di Kabupaten Garut. Desain penelitian yang digunakan adalah survey deskriptif dengan unit analisis berupa 42 kecamatan di Kabupaten Garut. Obyek penelitian adalah produksi sektor pertanian dan kondisi sarana prasarana ekonomi dan sosial yang berada di Kabupaten Garut. Hasil penelitian menunjukkan bahwa komoditas pertanian unggulan untuk dikembangkan adalah tanaman pangan padi sawah, kacang tanah, kedelai, jagung dan ubi kayu serta tanaman hortikultura kentang, cabe besar, wortel, tomat, alpukat, jeruk keprok, pisang dan pepaya. Komoditas unggulan pertanian tersebut menunjukkan kecenderungan terlokalisasi di beberapa kecamatan. Sebanyak 31 Kecamatan $(73,81$ \%) memiliki kecenderungan spesialisasi kegiatan pertanian sedangkan 11 kecamatan (26,19 \%) lainnya tidak mengkhususkan kegiatan pertaniannya pada komoditas tertentu. Kecamatan Garut dan Karangpawitan merupakan titik pertumbuhan. Terdapat enam Kecamatan sebagai pusat pelayanan utama, 13 kecamatan sebagai pusat pelayanan lokal dan 23 Kecamatan menjadi pusat pelayanan terkecil.
\end{abstract}


Kata kunci: Keunggulan komparatif, Pusat pertumbuhan, Pusat pelayanan.

\section{PENDAHULUAN}

Selama ini Kabupaten Garut telah dikenal sebagai sentra produksi tanaman pangan, sayuran dan buahbuahan serta perkebunan yang potensial di Jawa Barat. Pada tahun 2008 sektor pertanian memberi sumbangan terbesar terhadap perekonomian Kabupaten Garut yaitu Rp 7.912,94 miliar (38,86\%) dari total pendapatan kotor daerah (PDRB) atas dasar harga berlaku. Kondisi tersebut dapat dimengerti, karena perekonomian wilayah Garut masih didominasi oleh sektor pertanian. Sebagian besar penduduknya bermata pencaharian di sektor pertanian serta hampir $75 \%$ lahan di wilayah Kabupaten Garut digunakan untuk kegiatan di sektor pertanian (Pemda Garut, 2009).

Secara administrasi Kabupaten Garut memiliki wilayah cukup luas yaitu 306.519 ha yang terbagi menjadi 42 kecamatan dengan sekitar 419 desa per kelurahan. Jika wilayah pedesaan dikembangkan maka sedikitnya sebanyak $75 \%$ penduduk tersentuh oleh pembangunan tersebut. Sebaliknya bila pembangunan tidak diarahkan ke wilayah pedesaan, maka sebagian besar penduduk tidak dapat menikmati pembangunan yang akan berpengaruh terhadap penurunan produktivitas pertanian.

Secara spasial basis pembangunan pertanian adalah pembangunan pedesaan. Oleh karena itu pembangunan pedesaan di daerah sentra produksi melalui pengembangan pusat pertumbuhan perlu lebih dimantapkan agar memiliki keunggulan komperatif dan keberlanjutan (Departemen Pertanian, 2002). Pendapat ini sejalan dengan pemikiran Anderson \& Pradya-Lorch (2003) yang mengemukakan perlunya memfasilitasi pertumbuhan pertanian dan pembangunan pedesaan melalui perbaikan infrastruktur pedesaan, pasar dan perbaikan aksesibilitas terhadap input. Infrastruktur ekonomi yang memadai merupakan prakondisi bagi perkembangan kegiatan agribisnis dan perekonomoian di pedesaan.

Selama ini agroindustri dianggap dapat mempercepat pertumbuhan ekonomi wilayah pedesaan dan menunjukkan rantai dan cabang usaha yang terkait dengan sektor pertanian dan industri. Desa-desa memiliki potensi yang besar di sektor pertanian dan memiliki keunggulan komparatif sehingga pembangunan ekonominya harus berdasarkan sumber daya alam dan pertanian. Sehubungan dengan itu diperlukan pengkajian komprehensif ter- hadap karakteristik wilayah pedesaan dan kegiatan usaha pedesaan dengan keunggulan komparatif. Pengetahuan mengenai keunggulan komparatif suatu daerah sangat membantu kelancaran pembangunan pertani-an di daerah yang bersangkutan. Kegiatan dan komoditas potensial yang ada diharapkan dapat menjadi tulang punggung perekonomian wilayah guna mempercepat integrasinya ke dalam struktur pusat-pusat pertumbuhan regional.

Pada dasarnya pusat wilayah mempunyai hierarki yang ditentukan oleh jumlah penduduk serta jumlah dan jenis fasilitas umum yang tersedia (Budiharsono, 2001). Kota Kecamatan sebagai pusat pertumbuhan dan pelayanan harus dapat menyediakan fasilitas-fasilitas pelayanan yang diperlukan oleh masyarakat setempat. Agar fasilitas pelayanan tersebut efektif dan efisien, penyebarannya dapat dikonsentrasikan pada titik tertentu berdasarkan hiearkinya. Konsentrasi tersebut akan menguntungkan karena dapat menghemat dana anggaran pembangunan dan menghindarkan duplikasi pembangunan. Pemusatan fasilitas pelayanan tersebut merupakan bentuk usaha mengkonsentrasi-kan kegiatan pembangunan. Penelitian ini bertujuan untuk mengetahui komoditas pertanian yang menjadi unggulan untuk dikembangkan di Kabupaten Garut, dan sistem hierarki pusat-pusat pelayanan dan pertumbuhan yang mendukung pengembangan wilayah di Kabupaten Garut.

\section{BAHAN DAN METODE}

Desain penelitian yang digunakan adalah survey deskriptif dengan unit analisis 42 kecamatan di Kabupaten Garut dan obyek penelitiannya adalah produksi sektor pertanian dan kondisi sarana prasarana ekonomi dan sosial. Data yang digunakan adalah data sekunder dari arsip, catatan, dokumen dan informasi Bappeda, Dinas Pertanian dan BPS Kabupaten Garut. Teknik analisis data menggunakan analisi Location Quotient (LQ), analisis Koefisien Lokalisasi $(\alpha)$, analisis Koefisien Spesialisasi $(\beta)$, analisis ketersediaan fasilitas sosial ekonomi, metode Skalogram dan metode Skorsentralitas.

\section{Analisis Location Quatient, Koefisien Lokalisasi dan Spesialisasi}

Penilaian potensialitas pertanian dalam penelitian ini dilihat dari tingkat produksi dan dianalisis dengan analisis Location quotient (LQ), Koefisien lokalisasi $(\alpha)$ dan spesialisasi $(\beta)$. Location quotient merupakan 
perbandingan antara produksi relatif suatu sektor dalam suatu daerah dengan total produksi relatif sektor pada tingkat daerah yang lebih luas sebagai petunjuk adanya keunggulan komparatif suatu wilayah bagi sektor yang telah lama berkembang (Tarigan, 2004). Koefisien lokalisasi adalah indikator untuk melihat penyebaran kegiatan pertanian di suatu daerah sedangkan koefisien spesialisasi adalah indikator untuk melihat ada tidaknya spesialisasi kegiatan pertanian di suatu daerah.

$$
\begin{gathered}
\mathrm{LQ}=(\mathrm{Si} / \mathrm{Ni}) /(\mathrm{Si} / \mathrm{N}) \text { atau }(\mathrm{Si} / \mathrm{S}) /(\mathrm{Ni} / \mathrm{N}) \\
\alpha=\mathrm{Si} / \mathrm{Ni}-\mathrm{S} / \mathrm{N} \\
\beta=\mathrm{Si} / \mathrm{S}-\mathrm{Ni} / \mathrm{N}
\end{gathered}
$$

dimana:

Si: Jumlah produksi sektor i di tingkat kecamatan

S: Jumlah produksi seluruh sektor di tingkat kecamatan

$\mathrm{Ni}$ : Jumlah produksi sektor i di tingkat kabupaten

$\mathrm{N}$ : Jumlah produksi seluruh sektor di tingkat kabupaten

\section{Analisis Hierarki Pusat Pertumbuhan}

Pada penelitian ini dilakukan pengelompokan ketersediaan sumberdaya manusia dan saranaprasarana pendukung aktivitas sosial ekonomi dalam kategori, sedang dan tinggi. Peringkat pusat pertumbuhan diperoleh dengan metode Skorsentralitas dan Skalogram. Setelah peringkat pusat pertumbuhan dan fasilitas pelayanan diketahui, struktur dan organisasi tata ruang wilayah Kabupaten Garut dapat diketahui.

\section{HASIL DAN PEMBAHASAN}

\section{Komoditas Basis dan Lokalisasi Kegiatan Pertanian di Kabupaten Garut}

Jika penetapan komoditas unggulan maka hanya berda-sarkan data produksi komoditas maka komoditas lama yang telah menjadi trade mark (lokal spesifik) akan tersisihkan (Djuwendah, 2006). Oleh karena itu dipertimbangkan juga komoditas unik unggulan daerah seperti jeruk keprok yang lebih dikenal sebagai jeruk Garut, walaupun produksinya relatif kecil.

Berdasarkan analisis LQ dan $\alpha$, diperoleh 14 komoditas pertanian yang berpotensi menjadi komoditas unggulan di Kabupaten Garut (Tabel 1). Pada kelompok tanaman pangan, padi sawah menempati posisi pertama yang tersebar di 33 kecamatan dengan kemampuan menghasilkan padi melebihi kebutuhan wilayahnya. Pada kelompok tanaman hortikultura, kentang menduduki peringkat pertama yang tersebar di 17 kecamatan sentra selanjutnya diikuti oleh pisang yang tersebar di 33 kecamatan sentra.

Berdasarkan analisis koefisien lokalisasi $(\beta)$, 33 kecamatan (78,57 \%) melakukan spesialisasi kegiatan pertanian pada beberapa komoditas tertentu (Tabel 2). Sedangkan 9 kecamatan lainnya (21,53\%) memiliki kecenderungan tidak melakukan kegiatan pertanian pada beragam komoditas.

Menurut Direktorat jenderal Penataan Ruang Departemen Pemukiman dan Prasarana Wilayah (2003), suatu wilayah pertanian sebaiknya dikembangkan menjadi kawasan agropolitan yang

Tabel 1. Koefisien lokasi (LQ) dan lokalisasi ( $\alpha$ ) komoditas Pertanian Kabupaten Garut

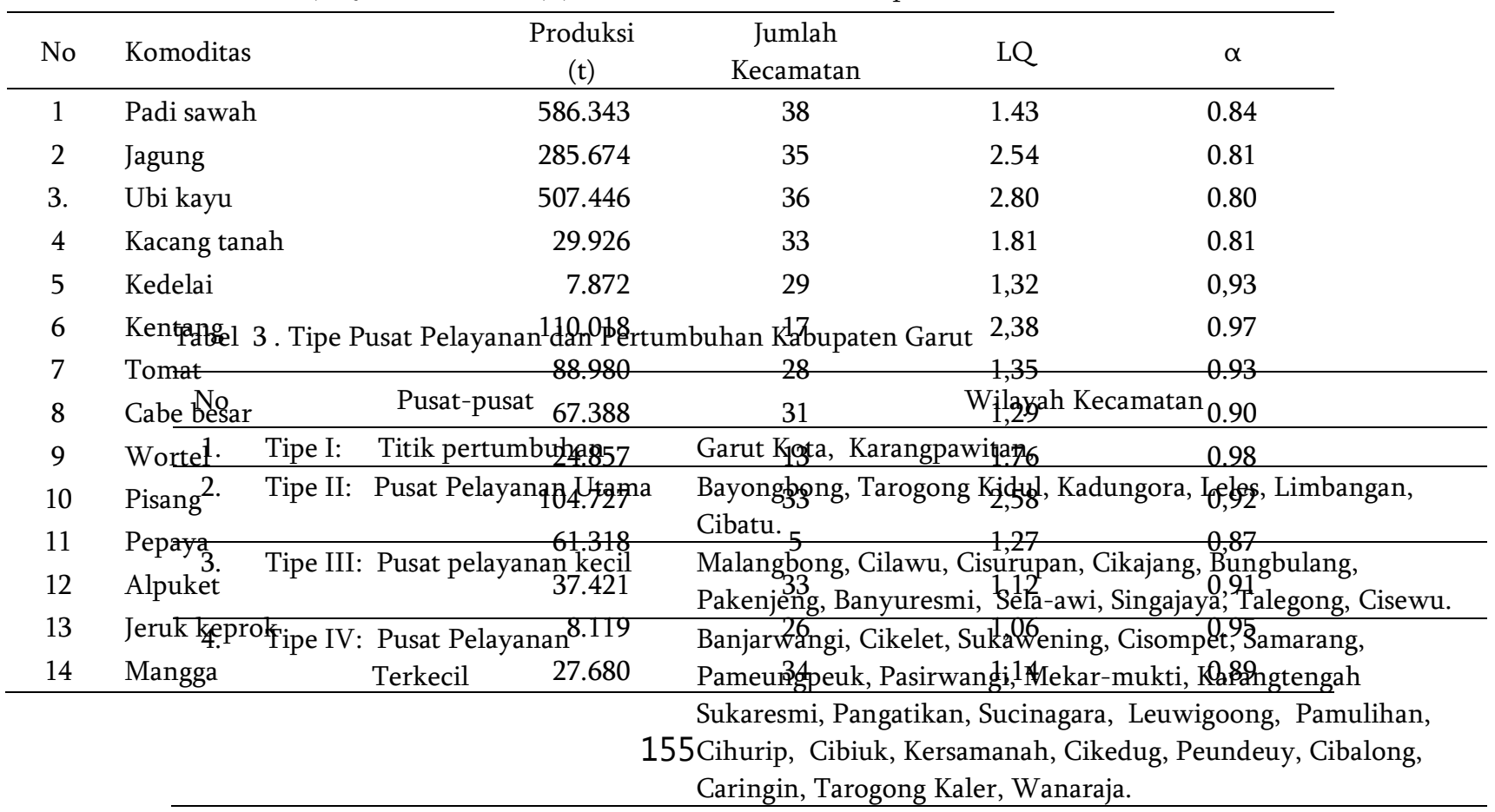


ditunjang oleh ketersediaan sumberdaya lahan dengan agroklimat yang sesuai. Pengembangan juga sebaiknya mencakup sarana dan prasarana agribisnis dan sosial yang memadai serta upaya menjaga kelestarian alam dan lingkungan hidup (Iqbal dan Setiadji, 2002). Oleh karena itu guna mendorong pertumbuhan wilayah berbasis komoditas pertanian unggulan diperlukan pengembangan pusat-pusat pertumbuhan wilayah.

\section{Hierarki Pusat Pertumbuhan dan Pelayanan}

Analisis metode Skalogram dan Skorsentralitas dilakukan terhadap lima variabel penentu pusat pertumbuhan dan kawasan penyangganya (hinterland) yaitu jumlah penduduk, tingkat keterpusatan, aksesibiltas, ketersediaan fasilitas ekonomi dan fasilitas sosial. Berdasarkan analisis ini diperoleh tipe pusat pelayanan dan pertumbuhan wilayah Kabupaten Garut (Tabel 3).

Kecamatan Garut Kota dan Karangpawitan berada pada Tipe I yang merupakan titik pertumbuhan. Wilayah belakang yang dilayaninya terdiri atas pusat-pusat pelayanan utama dengan hierarki yang lebih rendah. Kecamatan-kecamatan sebagai pusat pertumbuhan ini harus mampu menjadi penggerak pembangunan bagi seluruh wilayah belakangnya dan dalam jangka panjang diharapkan mampu meningkatkan perekonomian Kabupaten Garut.

Kecamatan yang berfungsi sebagai pusat pelayanan utama meliputi 6 kecamatan (14,28\%) dan berperan untuk melayani pusat-pusat pelayanan kecil dengan hierarki yang lebih rendah. Kecamatan yang termasuk pusat pelayanan kecil berjumlah 11 $(26,19 \%)$ yang berperan untuk melayani pusat pelayanan terkecil dengan hierarki yang lebih rendah. Pusat pelayanan terkecil mencakup 23 kecamatan (54,76\%) dan bertugas hanya melayani desa-desa di sekitarnya.

Semakin banyak wilayah yang berada pada tipe tertinggi yaitu tipe I dan II akan semakin banyak juga wilayah integrasi karena memiliki keterkaitan fungsional dengan wilayah hinterlandnya. Hal ini sangat baik bagi wilayah belakang karena semakin dekat dengan pusat-pusat pelayanan dan pertumbuhan (Hanafiah, 1988). Sebaliknya semakin banyak wilayah yang berada pada tipe III dan IV berarti semakin sedikit wilayah interaksi sehingga ketimpangan wilayah semakin besar.

Berdasarkan hasil penelitian Wahid (2006), terdapat ketimpangan wilayah di Kabupaten Garut yang terkait dengan perbedaan keadaan geografis dan potensi fisik wilayah. Sebagian besar wilayah kaya berada di Garut Utara (SWP I) dan wilayah miskin berada di Garut Selatan (SWP II dan SWP III) kecuali Kecamatan Karang Tengah, Kersamanah dan Cibiuk. Pendapat yang sama dikemukakan oleh Achmad (2008) bahwa Kabupaten Garut merupakan salah satu kabupaten tertinggal di Indonesia berdasarkan penetapan oleh Kementerian Percepatan Pembangunan Daerah Tertinggal. Di Kabupaten Garut terdapat ketimpangan wilayah karena perkembangan fisik wilayah bagian utara lebih maju dibandingkan bagian selatan. Faktor geografis wilayah bagian selatan merupakan salah satu faktor utama penyebab ketimpangan tersebut.

Dalam kaitannya dengan pembangunan daerah Kabupaten Garut, pusat pelayanan dan pertumbuhan tipe I dan II ternyata berada pada Sub Wilayah Pembangunan ke satu (SWP I ), sedangkan tipe III dan IV pada umumnya berada pada Sub Wilayah Pembangunan ke dua dan ke tiga (SWP II \& SWP III). Dengan demikian pembangunan di sub wilayah pembangunan dua dan tiga harus lebih diprioritaskan lagi guna meningkatkan kinerja pemerintahan dan meningkatkan pelayanan kepada masyarakat

Salah satu misi yang diemban Pemerintah Daerah Kabupaten Garut adalah mengembangkan ekonomi kerakyatan berbasis agrobisnis, agroindustri dan pariwisata disertai pengembangan budaya lokal serta meningkatkan kuantitas dan kualitas infrastruktur wilayah sesuai dengan daya dukung dan fungsi ruang (Pemda Kabupaten Garut, 2008). Sejalan dengan beberapa hasil penelitian yang telah dilakukan maka diperlukan suatu konsep pembangunan wilayah di Kabupaten Garut yang sesuai dengan potensi dan karakteristik daerah setempat. Konsep ini akan mengurangi ketertinggalan sekaligus memacu per-tumbuhan ekonomi yang akan berpengaruh terha-dap tingkat kesejahteraan masyarakat Kabupaten Garut.

\section{SIMPULAN DAN SARAN}

\section{Simpulan}

Di Kabupaen Garut terdapat 14 Komoditas basis pertanian yang layak menjadi komoditas unggulan yaitu padi sawah, kacang tanah, ubi kayu,kedelai, jagung, kentang, cabe besar, wortel, tomat, alpuket, jeruk keprok, mangga, pisang, dan pepaya. Umumnya komoditas basis pertanian tersebut terlokalisasi di beberapa kecamatan. Sebanyak 31 Kecamatan (73,81 \%) melakukan spesialisasi kegiatan pertanian sedangkan 11 kecamatan (26,19\%) tidak mengkhususkan kegiatan pertaniannya pada komoditas tertentu. 
Kecamatan Garut Kota dan Karangpawitan merupakan titik pertumbuhan. Kecamatan ini menjadi penggerak pembangunan bagi seluruh wilayah belakangnya. Kecamatan Bayongbong, Tarogong kidul, Kadungora, Leles, Limbangan dan Cibatu berfungsi sebagai pusat pelayanan utama dan wilayah belakang yang dilayani terdiri atas pusatpusat pelayanan kecil dengan hierarki yang lebih rendah.

\section{Saran}

Pusat pelayanan dan pertumbuhan Tipe I dan II berada di sub wilayah pembangunan ke satu (SWP I), sedangkan tipe III dan IV berada pada sub wilayah pembangunan ke dua dan ke tiga (SWP II dan SWP III). Dengan demikian pembangunan sarana dan prasarana sosial dan ekonomi di SWP I dan SWP II harus lebih diprioritaskan lagi guna meningkatkan kinerja pemerintahan, meningkatkan pelayanan kepada masyarakat sekaligus memacu pertumbuhan ekonomi yang akan berpengaruh terhadap tingkat kesejahteraan masyarakat Kabupaten Garut.

\section{UCAPAN TERIMAKASIH}

Terimakasih kepada semua pihak yang telah membantu dalam penelitian ini, terutama kepada Lembaga Penelitian Universitas Padjadjaran yang menyediakan dana penelitian serta Bappeda, Biro Pusat Statitsik dan Dinas Pertanian Kabupaten Garut untuk data sekunder.

\section{DAFTAR PUSTAKA}

Anderson PP and R Pradya-Lorch, 2003. The Unfinished Agenda, International Food Policy Research institute, Washington.

Budiharsono, S. 2001, Teknis Analisis Pembangunan Wilayah Pesisir dan Lautan, Padnya Paramita, Jakarta.

Achmad, D. 2008. Studi Pengembangan Kawasan Agropolitan di Wilayah Garut Selatan (Studi kasus: Wilayah pembangunan di Kabupaten Garut)

http://digilib.itb.ac.id/gdl.php?mod=browse

\&op=read\&id=jbptitbpp-gdl-dickyachma-

28493 (Diakses 24 April 2009).

Direktorat Jenderal Penataan Ruang Departemen Pemukiman dan Prasarana Wilayah. 2003. Penyusunan Strategi Pengembangan Kawasan Agropolitan Terpadu.

Djuwendah, E. 2006. Pengembangan Agribisnis Komoditas Unggulan di Kabupaten Sumedang, Laporan Penelitian Lembaga Penelitian Unpad, Bandung.

Hanafiah, T. 1988. Pendekatan Wilayah dan pembangunan Pedesaan, Jurusan Sosek, Faperta IPB, Bogor.

Iqbal M dan I Setiadjie, 2002. Rancang Bangun Kebijakan Agropolitan dan Pengembangan ekonomi lokal menuju percepatan Pembangunan Wilayah, PSE Bogor.

http://pse.litbang.deptan.go.id/ind/pdffiles/ ART7-2d.pdf (Diakses 25 April 2009).

Pemerintahan Kabupaten Garut. 2009. Profil Ekonomi.

http://www.Garutkab.go.id/pub/static_men u/detail/ekonomi_profile_domestik.

(Diakses 24 April 2009).

Pemerintahan Kabupaten Garut. 2008. Policy brief Rancangan akhir RPJMD Kabupaten Garut tahun 2009-2014.

http://www.smeru.or.id/report/training/ menjembatani_penelitian_dan_kebijakan/ untuk_organisasi_advokasi/files/110.pdf (Diakses 24 April 2009).

Tarigan, R. 2004. Ekonomi Regional, Bumi Aksara Jakarta.

Wahid, A. 2006. Strategi Pembangunan Daerah Tertinggal, Studi Kasus di Kabupaten Garut. Skripsi PS Ekonomi Pertanian dan Sumberdaya Faperta IPB, Bogor. 